\title{
Analysis of influence of using catalyst and polar additives on engine performance and exhaust emission
}

In the paper researches of influence of using catalyst and polar additives on engine performance and emission of exhaust were carried out. The tests were made on diesel engine DuraTorq-TDDi/TDCi 16v with a capacity of $1998 \mathrm{~cm} 3$ produced by Ford company. Two additives were investigated: FMAX - catalytic additive to fuel and HDOS - polar additive to lubricating oil in different proportions. The results indicated that using tested additives has a positive effect on exhaust composition (lower concentrations of nitrogen oxides, soot and carbon monoxide) and also decreased fuel consumption.

Key words: catalytic additives, polar additives, diesel engine, exhaust

\section{Introduction}

Diesel fuel is the basic energy carrier which is used for driving self-ignition engines. As the fuel, it has to meet requirements specified in legal acts and norms. The most important features of the fuel is possibility of pumping, filtering, low corrosivity, chemical stability and ability of self-ignition characterized by cetane number $[1,2]$. On the quality of fuels for diesel engines also level of lubrication also has significant influence. Lubricating properties could be increased by addition high hydrocarbons and sulphur compounds. However, that additives could destroy construction materials used for fuel and lubrication systems. Sulphur has detrimental effect on heat and thermooxidative stability and tends to corrode the metal. In addition, products of burning the sulphur, sulphur dioxide and sulphur trioxide, form acids in water environment, what is the reason of corrosion of exhaust system and atmospheric air pollution. Due to necessity of reduction of sulfur content in petroleum products to value below $50 \mathrm{mg} / \mathrm{kg}$, their lubrication properties have deteriorated significantly [2, 3]. Therefore it is necessary to use a non-toxic and environmental friendly lubricating additives to the fuel. Actually, that standards could be met by used additives containing derivatives of fatty acid methyl esters (FAME) made of vegetable oils. On the European and world markets esters are used as additives to diesel fuel or in its pure form, as biodiesel. Biodiesel has a lot of benefits compared to conventional diesel fuel. The main of them are that biodiesel is biodegradable, doesn't include harmful substances and aromatic hydrocarbons. Additionally, biodiesel has higher cetane number, what improves external engines parameters and at the same time, at higher temperature of ignition ensures safety of storage. Esters has more than $20 \%$ of oxide bonded in fatty acids, what caused that combustion process is more effectively and emission of soot and particular matter to the atmosphere decreases [4-7].

\section{Fuel additive characteristic}

One of the factors affecting the engine performance and exhaust toxicity is efficiency of energy source, i.e. the fuel. In the case of vehicles already in use, the general efficiency of the drive source is the most important parameter of the assessment allowing calculations of the economic suitabil- ity of the vehicle. In turn, economics is the most important criterion when assessing vehicles used for commercial purposes.

On the automotive market there are available many products (additives to fuel) which improve the economy of the drive and exhaust emissions. One of them, the additive Fuel Maximizer (FMAX) developed by ProOne Extreme Lubricants company was tested. The producer of the additive provides information that the product decreases fuel consumption and exhaust emission, improves lubricating properties of diesel fuel, increases the engine efficiency and cleans fuel system and injectors [8]. Fuel Maximizer is a catalyser, which reduces a activation energy and improve the reaction of combustion of fuel. Additionally, according to the manufacturer, the combustion process is more effective with FMAX through fragmentation the large particles of fuel and acceleration of initiation of combustion reaction.

The Fuel Maximizer was tested in 2018 by Polish Automotive Industry Institute and got the certificate of that Institution [9]. The Laboratory confirmed that the diesel fuel with FMAX meets all fuel requirements according to standards PN/ISO and using that product is safe for the engine.

The second object of the tests was additive to lubricating oil Heavy Duty Oil Stabilizer (HDOS). That product among others extends the life of the oil, protects against extreme pressures, prevents oil burning and leaks, improves performance and reduces fuel consumption, etc. the producer recommends supplying to lubricating oil about 10 $20 \%$ volume of HDOS.

\section{Material and methods}

The main aim of the tests was to evaluate the effect of changes caused by addition products of ProOne Extreme Lubricants on engine parameters. The researches were conducted on the turbocharged diesel engine DuraTorqTDDi/TDCi 16v with a capacity of $1998 \mathrm{~cm}^{3}$ produced by Ford company. The engine was supplied by Common Rail fuel supplied system and got exhaust gas recirculation. With these solutions, the engine has met the EURO 3 standard [10]. The power unit has been used for 14 years and had mileage about 306000 km. In Fig. 1 full load characteristic of maximum load and power values for engine is 
presented. Considering the direct dependence of power and torque, authors of this publication, wishing to avoid duplication of information, will only discuss the course of torque curves. Before starting the tests, to stabilize the engine's operating conditions, the lubricating oil was changed for a new one, approved by the manufacturer Mobil 1 0W40 with the CF quality class. This type of oil has been used for the last 6 years in tested engine.

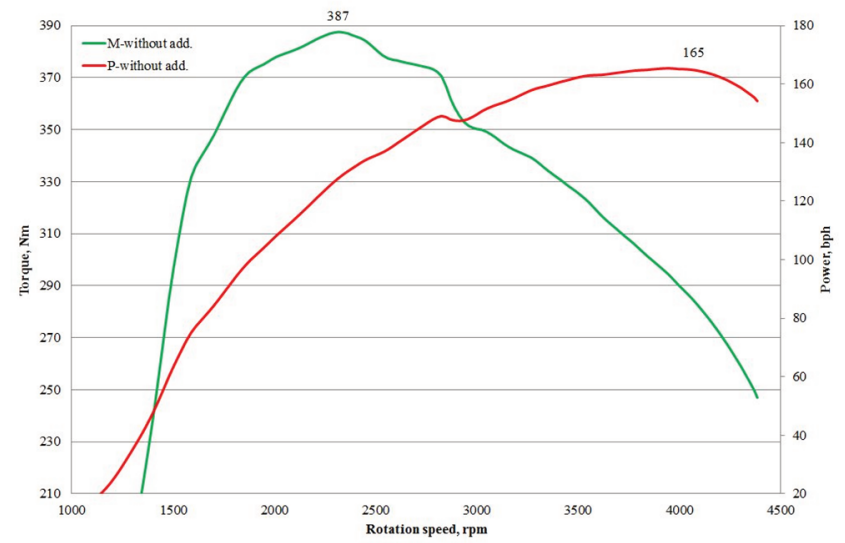

Fig. 1. Full load characteristic of tested engine supplied by diesel fuel without additives

Research was focused on the effect of used additives to fuel (FMAX) and to lubricating oil (HDOS) on parameters of engine's work such as correct operation of some systems (fuel supplied system, air intake system, engine control system, etc.) and exhaust concentrations. In the test full load characteristics were made for engine supplied by fuel without and with additive and without or with additive to lubricating oil. Characteristics were made on the chassis dynamometer MAHA LSP 3000. That tests allowed for evaluation maximum engine performance. Additionally, in chosen points of engine's work (with constant load of engine) measurements of exhaust concentration were conducted. The following components of fumes were analysed:

- nitrogen oxides $\left(\mathrm{NO}_{\mathrm{x}}\right)$, carbon monoxide $(\mathrm{CO})$, carbon dioxide $\left(\mathrm{CO}_{2}\right)$, oxygen $\left(\mathrm{O}_{2}\right)$ measured with used Horiba PG 350 analyser $\left(\mathrm{NO}_{x}\right.$ by chemiluminescence detection method CLD; $\mathrm{CO}$ and $\mathrm{CO}_{2}$ by non-dispersive infrared method NDIR; $\mathrm{O}_{2}$ by galvanic cell method), accuracy of the measurement was $\pm 0,5 \%$ in range $\mathrm{NO}_{\mathrm{x}} \geq 100 \mathrm{ppm}$ and $\pm 1 \%$ for other substances in full range;

- soot with used AVL 415 smoke meter, which is able to measure soot concentration in units FSN (filter smoke number) or in $\mathrm{mg} / \mathrm{m}^{3}$ with measurement range to 0,02 $\mathrm{mg} / \mathrm{m}^{3}$.

Additionally, during the tests conditions were controlled using weather station HD32.1 produced by Delta OHM company. Accuracy of temperature measurement of the device is $\pm 0.1^{\circ} \mathrm{C}$.

The engine work conditions for exhaust composition measurement were selected to cover the engine operation areas with closed and open EGR valve. In table 1 characteristic of chosen points of engine work conditions are presented.
Table 1. Characteristic of points of engine operation conditions

\begin{tabular}{|l|c|c|c|}
\hline No. & $\begin{array}{c}\text { Rotation } \\
\text { speed, } \\
\text { rpm }\end{array}$ & $\begin{array}{c}\text { Power, } \\
\text { bhp }\end{array}$ & \multicolumn{1}{c|}{ Comments } \\
\hline 1 & 2100 & 10 & $\begin{array}{l}-\quad \text { low engine load value (low air flow } \\
\text { and dose of fuel), } \\
\text { opened EGR valve (large propor- } \\
\text { tion of exhaust in fresh inlet air) }\end{array}$ \\
\hline 2 & 2100 & 50 & $\begin{array}{l}-\quad \text { medium engine load, } \\
\text { tion of exhaust) }\end{array}$ \\
\hline 3 & 3000 & 65 & $\begin{array}{l}-\quad \text { rotation speed close to nominal, } \\
-\quad \text { medium engine load, } \\
\text { closed EGR valve }\end{array}$ \\
\hline 4 & 760 & idle & $\begin{array}{l}- \text { important point to evaluation of } \\
\text { engine work in city traffic }\end{array}$ \\
\hline
\end{tabular}

Three variants of supplying the engine were tested: diesel fuel without any additives, with FMAX as additive to fuel in proportion 1:4000 (manufacturer's recommendations) and 1:1000 (four times greater than manufacturer's recommendations) and with HDOS as additive to lubricating oil, and the last, with FMAX as additive to fuel in proportion 1:4000 and with HDOS.

\section{Results and discussion}

In Figure 2 results of full load characteristic for three variants of tests (pure diesel fuel with FMAX in proportion 1:4000 and fuel with FMAX and lubricating oil with HDOS) are presented.

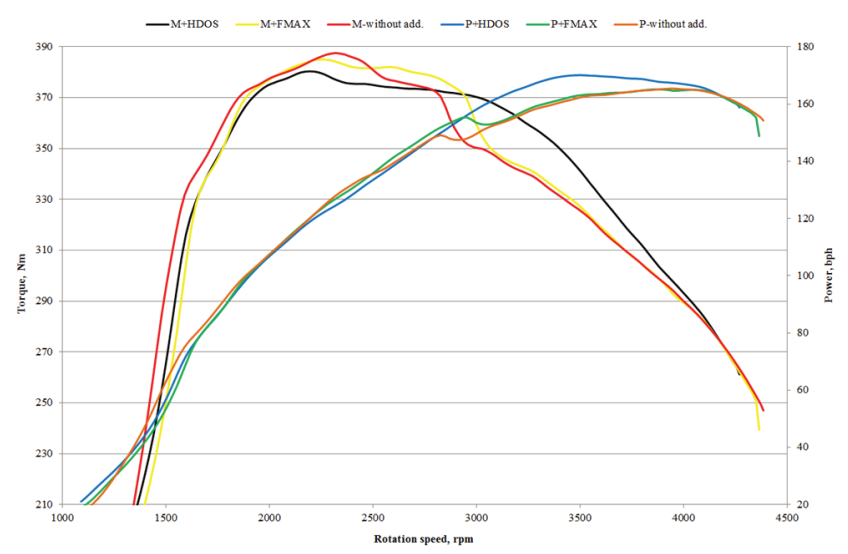

Fig. 2. Results of full load characteristic conducted on the chassis dynamometer

As it can be noticed, the highest torque value is obtained for pure diesel fuel, but in case with FMAX as additive to fuel in proportion 1:4000, the range of high torque values is the widest, between 1700 and $3000 \mathrm{rpm}$. The best course of power curve was registered in test with FMAX as additive to fuel and HDOS as additive to lubricant oil. Power for variants with pure diesel fuel and for FMAX was similar.

In the test also concentrations of ingredients of exhaust for all variants were measured. In Figs 3-5 measured concentrations of toxic components of exhaust such as $\mathrm{NO}_{\mathrm{x}}$, soot and $\mathrm{CO}$ are shown and in figures 6 and 7 respectively concentrations of $\mathrm{CO}_{2}$ and $\mathrm{O}_{2}$.

From the figures appears that the lowest concentrations of all of analysed toxic components in each measuring point were obtained for variant with diesel fuel and FMAX in proportion 1:1000. In point 1 (at $2100 \mathrm{rpm}$ and $10 \mathrm{Nm}$ ) 
concentrations of $\mathrm{NO}_{\mathrm{x}}$ for all variants are similar. It may be due to similar content of oxygen (Fig. 7) and temperature of combustion process in low load. Generally, it was noticed that concentration of $\mathrm{NO}_{\mathrm{x}}$ was the highest in the first variant - with pure diesel fuel and using any additive allows reduce $\mathrm{NO}_{\mathrm{x}}$ emission. Emission of soot is the highest for pure diesel almost in all of measuring points. Only in point 2 (at $2100 \mathrm{rpm}$ and $50 \mathrm{Nm}$ ) is the lowest for that variant. In terms of emission $\mathrm{CO}$, the worst results were obtained for mixture of fuel and FMAX in proportion 1:4000 in points 1, 3 and 4 and for pure diesel oil in point 2 . On the other side, the lowest $\mathrm{CO}$ concentrations measured for variant with FMAX added to diesel fuel in proportion 1:1000.

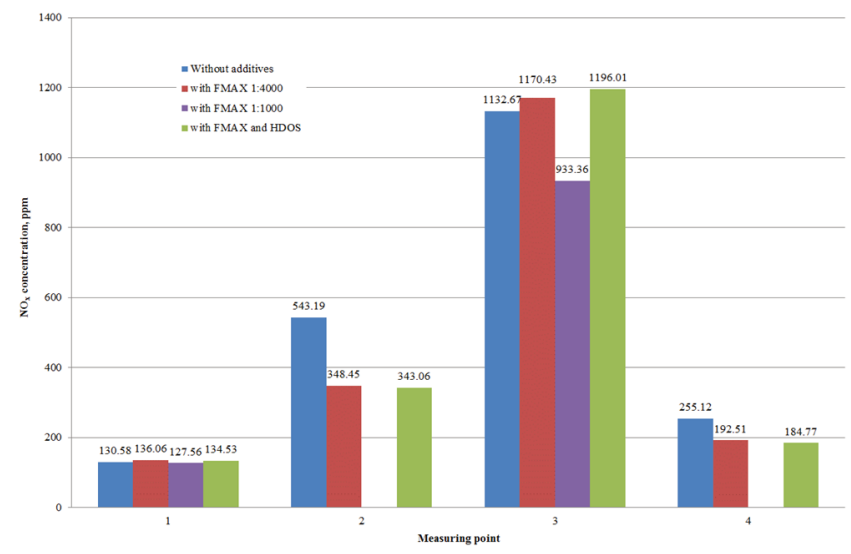

Fig. 3. Concentrations of $\mathrm{NO}_{\mathrm{x}}$ measured in tests

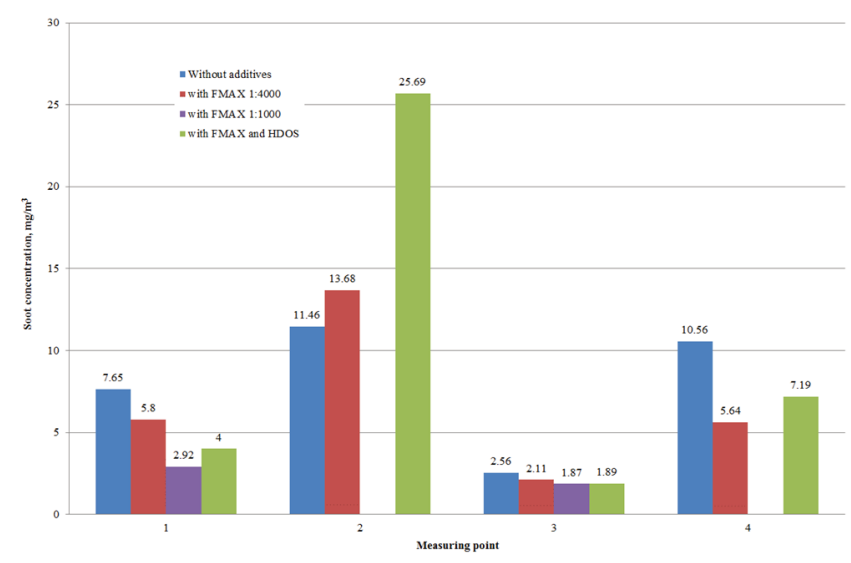

Fig. 4. Concentrations of soot measured in tests

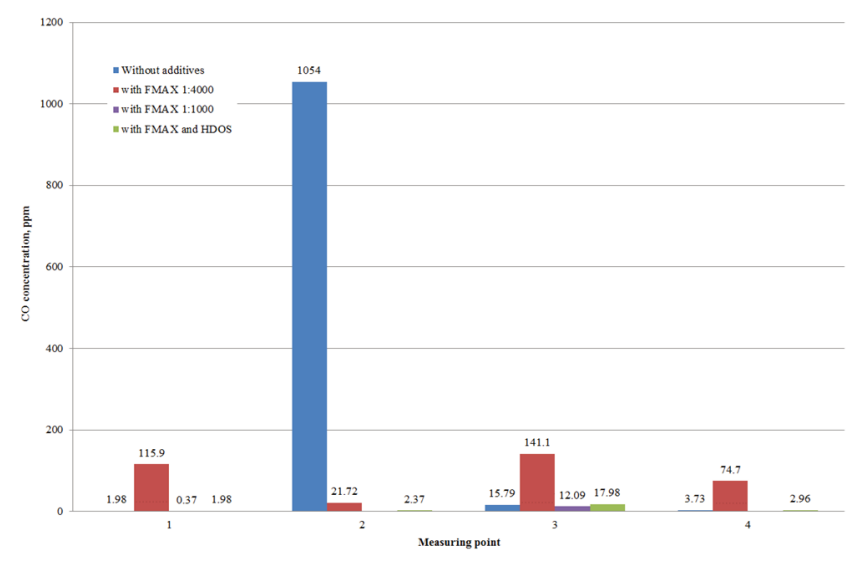

Fig. 5. Concentrations of CO measured in tests

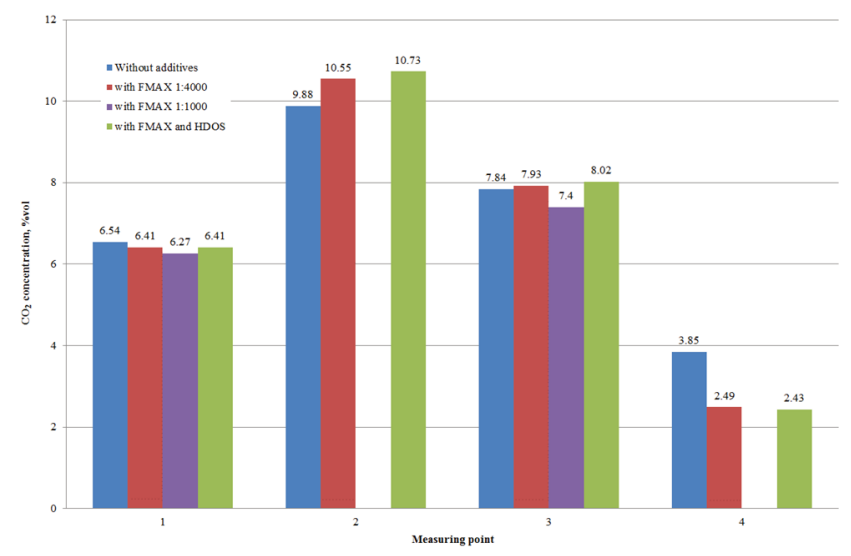

Fig. 6. Concentrations of $\mathrm{CO}_{2}$ measured in tests

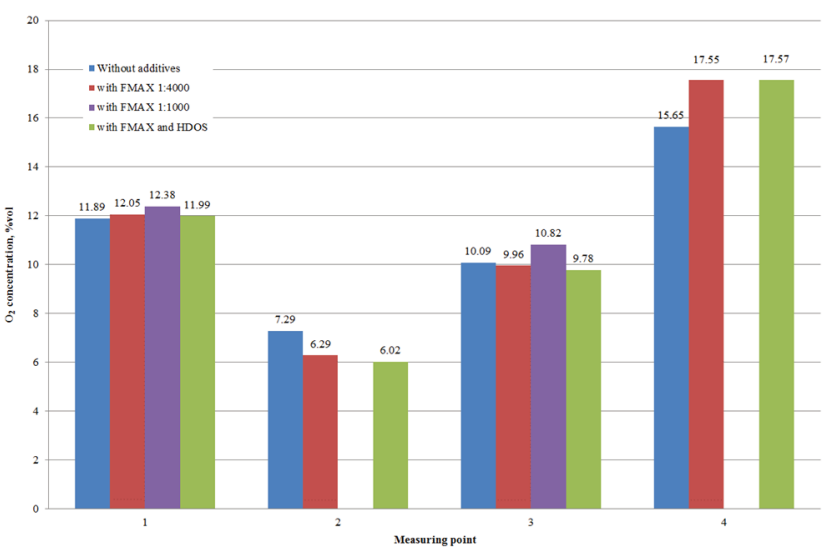

Fig. 7. Concentrations of $\mathrm{O}_{2}$ measured in tests

In all points of engine's work (except point 2) concentration of $\mathrm{CO}_{2}$ were lower for at least one variant with additive that for variant with pure diesel fuel. In addition, content of $\mathrm{O}_{2}$ was highest in variants with additives. It could testify to reducing of fuel consumption in case of using FMAX and HDOS as additives to fuel and lubricant oil. The best result was received for variant with FMAX with fuel in proportion 1:1000.

\section{Summary and conclusion}

In the paper additives to diesel fuel (FMAX) and to lubricant oil (HDOS) produced by company ProOne Extreme Lubricants were tested, in terms of engine performance and content of exhaust gases. In researches turbocharged diesel engine DuraTorq-TDDi/TDCi 16v with a capacity of 1998 $\mathrm{cm}^{3}$ produced by Ford company was used. Tests was carried out in 4 variants:

1) combustion of pure diesel fuel

2) combustion of diesel fuel with added FMAX in proportion 1:4000

3) combustion of diesel fuel with added FMAX in proportion 1:1000 and with HDOS as additive to lubricant oil

4) combustion of diesel fuel with added FMAX in proportion 1:4000 and with HDOS as additive to lubricant oil

Measurements of concentration of toxic compounds of exhaust such as $\mathrm{NO}_{\mathrm{x}}$, soot and $\mathrm{CO}$ were made. Also the full load characteristic for 3 of variants were prepared. Additionally $\mathrm{CO}_{2}$ and $\mathrm{O}_{2}$ content in fumes was analysed. 
Based on the results it was noticed that generally additions to diesel and lubricant oil had positive influence on combustion process in relation to emission of exhaust and fuel consumption, but not so good in terms of achieved the maximum torque - the maximum value was obtained for pure diesel fuel. However, the torque above $370 \mathrm{Nm}$ engine achieved in wider range for tests with additives. Also the maximum value of power is the higher for diesel oil with additives, especially FMAX with HDOS. Producer recommends using FMAX in proportion with fuel 1:4000. As in was presented in previous chapter with results, benefits of using mixture in that composition was well in a lot of points of engine operations, but even better results was obtained in proportion FMAX with fuel 1:1000. Concentration of $\mathrm{NO}_{\mathrm{x}}$ for that variant was reduced by an average of $10 \%$, concentration of soot of $45 \%$ and CO more than $50 \%$.

\section{Acknowledgements}

The authors of the article would like to special thank the company Lubrication Plus Business Consulting AB Bogdanowicz Artur for sharing research materials documented in this publication.

\section{Bibliography}

[1] KARDASZ, K., KĘDZIERSKA, E., KONOPKA, M. et al. Fatty acid methyl esters as diesel oil lubricating additive, Exploitation Problems. 2003, 1, 191-201.

[2] MITCHELL, K. Lubricity of winter diesel fuels. SAE Technical Paper 952370, 1995. DOI:10.4271/952370.

[3] Essential methods of the quality assessment of industrial lubricants and their exploitation meaning, Total. Part IV, ELF Company Information. 2002, 8-26.

[4] SULEK, M.W., KULCZYCKI, A., MALYSA, A. Quality assessment of fuels based on biocomponents. Polish Journal of Commodity Science. 2006, 2(7), 30-40.

[5] SULEK, M.W., KULCZYCKI, A., MALYSA, A. Lubricating properties of fatty acid methyl esters and fuel oil compositions. Tribology. 2006, 2.
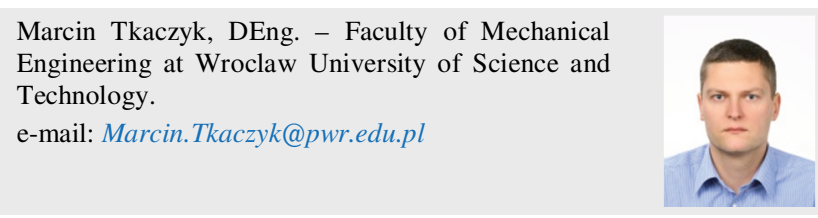

Konrad Krakowian, DEng. - Faculty of Mechanical Engineering at Wroclaw University of Science and Technology.

e-mail: Konrad.Krakowian@pwr.edu.pl
[6] GELLER, D.P., GOODRUM, J.W. Effects of specific fatty acid methyl esters on diesel fuel lubricity. Fuel. 2004, 83, 2351-2356.

[7] WAIN, K.S., PEREZ, J.M., CHAPMAN, E. et al. Alternative and low sulfur fuel options: boundary lubrication performance and potential problems. Tribology International. 2005, 38, 313-319. DOI:10.1016/j.triboint.2004.08.014.

[8] ProOne Extreme Lubricants information materials;

[9] Research report of Polish Automotive Industry Institute "Tests of physical and chemical parameters for the supplied sample according the order" no. PLN.022.18B/Z1, 19.03. 2018.

[10] www.motodiesel.pl/silniki/3015-silnik-20-duratorq-tdci.html. Access: 26.10.2018.

Maria Skrętowicz, DEng. - Faculty of Mechanical Engineering at Wroclaw University of Science and Technology.

e-mail: Maria.Skretowicz@pwr.edu.pl 